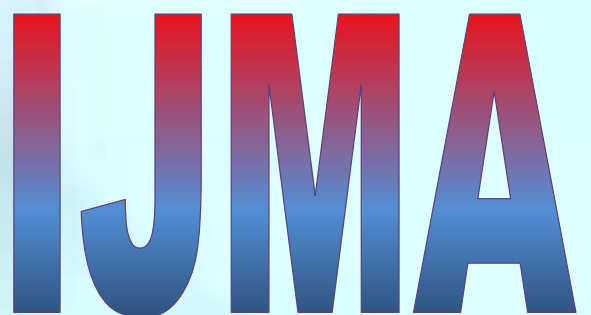

INTERNATIONAL

Journal of MEdical

\section{ARTS}

Volume 3, Issue 1 (Winter 2021)

http://ijma.journals.ekb.eg/

Print ISSN: 2636-4174

Online ISSN: 2682-3780

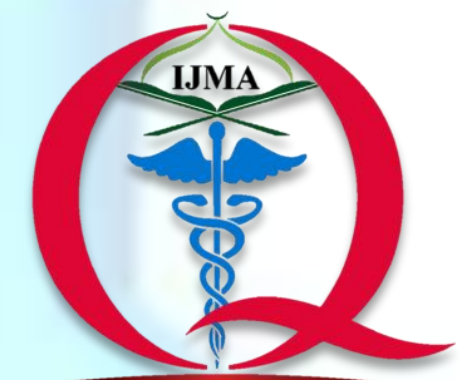

International Jounnal of Medical Arts

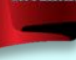




\section{About IJMA}

- International Journal of Medical Arts is the Official Journal of the Damietta Faculty of Medicine, Al-Azhar University, Egypt

- The First Issue was published in July 2019

- It is an International, Open Access, Double-blind, Peerreviewed Journal

- Published four times a year

- Published under the following license: Creative Commons Attribution-ShareAlike 4.0 International Public License (CC BY-SA 4.0). It had updated from the Creative Commons license [CC BY] in volume 2, Issue 4, October 2020

- The Egyptian Knowledge Bank hosts the web site of IJMA

- The Egyptian Knowledge Bank supports IJMA

- IJMA is indexed in the "Directory of Open Access Journals" Indexed on 15 January 2021.

- IJMA follows the regulations of the International Committee of Medical Journal Editors (list date 1/21/20)

- IJMA is a member of The International Society of Managing and Technical Editors

- IJMA is listed in Index Copernicus

- IJMA is listed in Publons, as EKB is an official partner with Clarivate Analytics
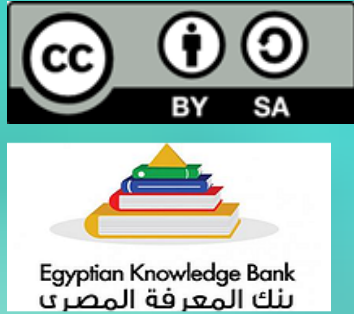

\section{DOAJ}

CMNE

ISMTE

INDEX COPERNICUS

publons 


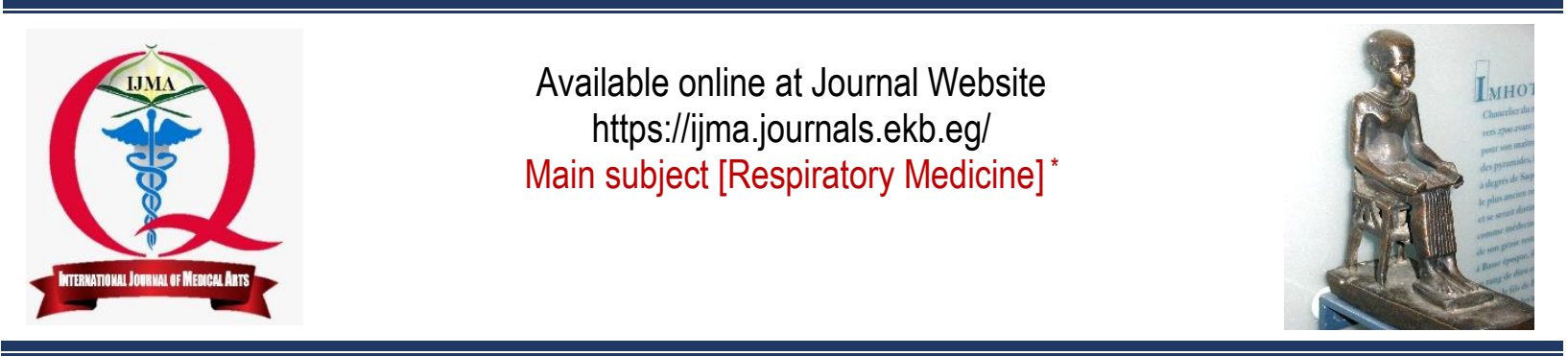

Original article

\title{
Value of Ultrasound in the Management of Acute Respiratory Distress Syndrome by Optimal PEEP
}

\author{
Ali Mohamed Ali Abdelhameed [1], Atef Wahdan Saleh [1], Abdelhay Ibraheem Abdelhay [2] \\ Department of Chest Diseases, Damietta Faculty of Medicine, Al-Azhar University, Egypt[1]. \\ Department of Chest Diseases, Faculty of Medicine, Al-Azhar University, Egypt [1].
}

Corresponding author: Atef Wahdan Saleh

Email:atefchest@gmail.com

Received at: August 25, 2020; Revised at: 20-9-2020; Accepted at: September 29, 2020

DOI: 10.21608/IJMA.2020.116075

\section{ABSTRACT}

Background: Acute respiratory distress syndrome [ARDS] is usually associated with significant morbidities and may need admission to the intensive care unit [ICU]. Mechanical ventilation, when indicated, needs continuous monitoring.

Aim of the work: To assess the clinical value of ultrasonic monitoring in pulmonary recruitment and optimal positive end-expiratory pressure [PEEP] in ARD cases.

Methods: It included thirty patients with ARDS. All were subjected to clinical evaluation, X-ray chest, lung ultrasound, and laboratory investigations. All patients underwent mechanical ventilation by increasing PEEP, starting at $5 \mathrm{mmHg}$ then $[6,9,12$, and $15 \mathrm{mmHg}$ ] according to patient response with documentation of good response. At each PEEP, a chest ultrasound was completed, and results were correlated with respiratory functions.

Results: Hypertension, diabetes, COPD and hypothyroidism were reported in $63.3 \%, 66.7 \%, 16.7 \%$ and $40.0 \%$ respectively. The rate of primary weaning success was $36.7 \%$, and $30.0 \%$ achieved weaning success in the third trail; tracheostomy indicated for $13.3 \%$, pneumothorax $10.0 \%$, pleural effusion $6.7 \%$, and the mortality rate was $33.3 \%$. Increased PEEP was concomitant by the progressive improvement of respiratory functions. In addition, there was a progressive significant decrease of B-lines at different areas from right and left lungs. All effects were significant at PEEP 9.

Conclusions: Gradual increments of PEEP helps to tailor the patient response on an individual basis. The use of readily available, portable ultrasound permits the daily monitoring and could guide the treatment protocol.

Keywords: Acute Respiratory Distress Syndrome; Mechanical Ventilation; Lung Ultrasound; Positive End Expiratory Pressure; Blines.

This is an open-access article registered under the Creative Commons, ShareAlike 4.0 International license [CC BY-SA 4.0] [https://creativecommons.org/licenses/by-sa/4.0/legalcode]

Please cite this article: Abdelhameed AMA, Saleh AW, Abdelhay Al. Value of Ultrasound in the Management of Acute Respiratory Distress Syndrome by Optimal PEEP. IJMA 2021; 3[1]: 1104-1112. DOI: 10.21608/IJMA.2020.116075

${ }^{*}$ Main subject and any subcategories have been classified according to the research topic. 


\section{INTRODUCTION}

Diagnosis of acute respiratory distress syndrome [ARDS] is based on clinical, radiological, and oxygenation criteria; the imaging criteria consist of bilateral infiltration, not fully clarified by effusion, lobar/lung collapse, or nodules ${ }^{[1]}$.

In the last decades, radiological imaging of the lung [e.g., X-ray and computed tomography [CT]] have been extensively used in ARDS. Actually, bedside X-ray of the lung is a cardinal part of the standard diagnostic criteria of ARDS[2], as CT chest needs transportation of the patient, which exerts a risk on subjects with marked hypoxemia[3].

The US is increasingly used in intensive care units [ICUs]. The US is a noninvasive and reproducible imaging modality, which could be done at the bedside. Available data suggested that the US is useful for patients with ARDS. In such patients, the US can play a role in the establishment of ARDS diagnosis and to optimize the levels of positive endexpiratory pressure [PEEP] to prevent hemodynamic instability[4].

Lung US could be applied as the guide for PEEP, as it can be used in real-time monitoring; no need for deep sedatives or muscle relaxation; could be applied to discover the endpoint of lung recruitment, determine the optimal PEEP, and enhance lung compliance[5].

In addition, lung protective strategies are accompanied by improvement in patient outcomes and less comorbidities [6]. Accordingly, low tidal volumes must be administered to all cases, and high PEEP should be applied for subjects with moderate-to-severe ARDS. However, the determination of the optimal PEEP level is a challenging task, with a high risk of mortality ${ }^{[7]}$.

Previous trials proposed that the optimal PEEP level could be adjusted based on the oxygenation variables [8]. Others suggested that lung mechanics [e.g., compliance, plateau pressure, and stress index] must be used to determine optimal PEEP [9].

Imaging modalities, primarily CT chest, were also used to evaluate the effects of gradual increase of PEEP on recruitment of alveoli [10]. In recent decades, lung US has become increasingly applied as a substitution of CT for the determination of optimal PEEP[11].
Lung US can be a valuable tool to evaluate the lung aeration after increasing the levels of PEEP. Moreover, the assessment of the anterior, lateral, and posterior areas of the lung revealed that the value from PEEP was mostly perceived in the lower part of the anterior and lateral lungs as well as the upper and posterior part of the lungs. Re-aeration of the consolidated lung [either partially or total] was rarely detected and was occurred more often in the lower lungs lobes.

Finally, the US-guided recruitment strategy leads to significant enhancement of lung re-aeration when compared to oxygenation- guided approach[5]. However, the role of lung US as a monitoring and guide tool in patients with ARDS admitted to ICU is not well addressed.

\section{AIM OF THE WORK}

The aim of this study is to assess the clinical role of lung US monitoring for pulmonary recruitment and determination of optimal positive end-expiratory pressure in patients with ARDS.

\section{PATIENTS AND METHODS}

This prospective study was conducted in the department of chest disease, Al-Azhar University Hospital-Damietta, from November 2019 to August 2020. It was carried out on thirty [30] patients with ARDS. The inclusion criteria were: Age: $>18$ years old [adult], who had evidence of ARDS [acute onset, the deficit in oxygenation should $\mathrm{PaO}_{2} / \mathrm{fiO}_{2}<300$ $\mathrm{mmHg}$ irrespective of PEEP therapy and chest $\mathrm{X}$-ray should show bilateral infiltration that can not be explained by effusion, collapsed lung, or lung nodule and without any evidence of heart failure. On the other side, exclusion criteria were: intracranial hypertension, convulsion, pregnancy, presence of pneumothorax, bronchopleural fistula.

All patients were subjected to full history taking, physical examination, X-ray chest anteroposterior view by portable X-ray in ICU patient. In addition, lung ultrasound had been performed by the portable device.

The lung ultrasound was carried out as described by Dietrich et al.[12]. Lung ultrasound had advantages, including the absence of ionizing radiation, accessibility of necessary equipment, and the possibility of real-time bedside applications and 
image assessment. Thus, it is reasonable to be used in intensive care units. In addition, portable echocardiography was performed to exclude heart failure. Finally, the following laboratory investigations were performed: complete blood count [CBC], arterial blood gases [ABGs], C-reactive protein [CRP], random blood sugar, electrolytes, liver, and kidney function tests.

Ventilation: All patients underwent mechanical ventilation on the Newport machine, and positive end-expiratory pressure was applied and starting at $5 \mathrm{mmHg}$ [physiological PEEP], and gradual increments $[6,9,12$, and $15 \mathrm{mmHg}$ ] were used according to patient response, and the good response had been documented. At each PEEP, a chest ultrasound had been performed, and its results correlated with respiratory functions.

Ethical Considerations: The selection of subjects and the collection of specimens from them was done after a prior explanation of the aim of the study, and a free, well-written approval was taken. All work had been approved by the ethical committee, Damietta Faculty of Medicine [Al-Azhar University].

Statistical analysis of data: The collected data had been verified, coded, and fed to a computer; a statistical package for social sciences had been used for analysis. We used version 18 [SPSS Inc., USA]. Numerical variables are presented in the form of arithmetic mean and standard deviation, while categorical data are presented in relative number [frequency] and percentage. Data had been compared to the basic values by paired samples [t] test for numerical data and Wilcoxon signed ranks for categorical data.

\section{RESULTS}

Patient age ranged between 31 to 84 years [mean age was $51.50 \pm 16.25$ ]. In addition, the mean patient weight was $86.53 \pm 16.52 \mathrm{~kg}$, while the mean ideal body weight was $75.23 \pm 8.44 \mathrm{~kg}$; the mean body mass index [BMI] was 75.23 \pm 8.44$]$. Males represented $46.7 \%$, while females represented $53.3 \%$. Finally, hypertension, diabetes, COPD and hypothyroidism were reported in $63.3 \%, 66.7 \%$, $16.7 \%$ and $40.0 \%$ respectively [Table 1 ]

Regarding the cause of admission, diabetes was the cause among $6.7 \%$, hypothyroidism among
40.0\%, COPD among 16.7, and each of stoke, septic shock, and liver cell failure among 3.3\%, while chest infection $20.0 \%$ and renal failure among $6.7 \%$.

In the current work, the primary weaning success had been reported among 11 patients [36.7\%], and weaning success in the third trial had been registered among nine patients [30.0\%]; tracheostomy had been indicated for $13.3 \%$, pneumothorax had been reported among $10.0 \%$, pleural effusion among $6.7 \%$ and the mortality rate was $33.3 \%$ [Table 2].

In the current work, increased PEEP was associated with significant progressive increase of tidal volume among studied populations. A significant change had been reported at PEEP 15 $\mathrm{mmHg}$, as there is a significant increase at PEEP 15 when compared to each of PEEP 12, 9, 6, and 5. In addition, there was a statistically significant progressive increase of alveolar dead space ventilation among studied patients; a significant increase had been observed at PEEP 15, where there was a significant difference between PEEP15 and each of the previous lower values of PEEP. Also, there was a significant progressive increase of peak alveolar carbon dioxide tension with increased PEEP values; however, the paired comparison did not provide any significant differences. Partial arterial pressure of carbon dioxide exhibited nonsignificant different variability with increased PEEP. At PEEP 6 , it decreased when compared to PEEP 5, with a nonsignificant difference. Then, it increased with PEEPs, 9, 12, and 15 when compared to PEEPs 5 and 6. However, partial oxygen tension was significantly and progressively increased with increased PEEP from PEEP 6 to P15. The value between PEEP 15 and 12 was non-significant. Furthermore, $\mathrm{PaO}_{2} / \mathrm{FiO}_{2}$ significantly increased with a progressive increase of PEEP. The significant values were observed at PEEP 6 and continued afterward [Table 3].

Regarding the effect of PEEP on ultrasound Blines, there was a progressive significant decrease of B-lines at different areas from the right and left lungs. All effects were significant at PEEP 9, except for area $A 2$ on the right side, where the effect becomes marked at PEEP 6 [Table 4]. 
Table [1]: Baseline characteristics of the studied patients

\begin{tabular}{|l|c|}
\hline \multicolumn{1}{|c|}{ Variables } & Statistics \\
\hline Age [years] & $51.50 \pm 16.25$ \\
\hline Weight & $86.53 \pm 16.52$ \\
\hline Ideal body weight & $75.23 \pm 8.44$ \\
\hline BMl & $24.80 \pm 4.32$ \\
\hline Sex [male/female] & $14 / 16[46.7 \%] / 53.3 \%]$ \\
\hline Hypertension & $19[63.3 \%]$ \\
\hline Diabetes mellitus & $20[66.7 \%]$ \\
\hline COPD & $5[16.7 \%]$ \\
\hline Hypothyroidism & $12[40.0 \%]$ \\
\hline
\end{tabular}

Table [2]: Outcome among studied populations

\begin{tabular}{|l|l|c|c|}
\hline \multirow{2}{*}{ First weaning trial } & Failure & Frequency & Percent \\
\cline { 2 - 4 } & Success & 19 & 63.3 \\
\hline \multirow{2}{*}{ Third weaning trial } & Failed & 11 & 36.7 \\
\cline { 2 - 4 } & Succeeded & 10 & 33.3 \\
\hline Tracheostomy & & 9 & 30.0 \\
\hline Pneumothorax & & 4 & 13.3 \\
\hline Pleural effusion & 3 & 10.0 \\
\hline Mortality & 2 & 6.7 \\
\hline
\end{tabular}

Table [3]. Effect of PEEP on different respiratory parameters

\begin{tabular}{|l|c|c|c|c|c|c|c|}
\hline \multicolumn{1}{|c|}{ Variables } & PEEP5 & PEEP6 & PEEP9 & PEEP12 & PEEP15 & $\mathrm{F}$ & $\mathrm{p}$ \\
\hline $\mathrm{Vt}$ & $495.33 \pm 33.29$ & $498.66 \pm 37.39$ & $498.66 \pm 35.78$ & $500.33 \pm 34.88$ & $511.33 \pm 28.25$ & 6.98 & $0.001^{*}$ \\
\hline Vdalv & $23.07 \pm 6.64$ & $28.10 \pm 8.67$ & $26.07 \pm 7.66$ & $32.63 \pm 16.17$ & $71.23 \pm 16.49$ & 83.58 & $<0.001^{*}$ \\
\hline $\mathrm{P}_{\mathrm{AETCO}}$ & $4.48 \pm 1.10$ & $4.59 \pm 0.96$ & $4.67 \pm 0.92$ & $4.68 \pm 0.91$ & $4.68 \pm 0.91$ & 5.07 & $0.014^{*}$ \\
\hline $\mathrm{PaCO}_{2}$ & $40.30 \pm 1.86$ & $39.90 \pm 3.26$ & $42.07 \pm 3.61$ & $41.13 \pm 3.86$ & $40.97 \pm 2.71$ & 2.91 & 0.06 \\
\hline $\mathrm{PaO}_{2}$ & $116.73 \pm 9.42$ & $124.67 \pm 10.34$ & $130.60 \pm 10.34$ & $134.70 \pm 9.11$ & $137.93 \pm 9.78$ & 46.22 & $<0.001^{*}$ \\
\hline $\mathrm{PaO}_{2} / \mathrm{FiO}_{2}$ & $236.83 \pm 51.74$ & $277.8 \pm 66.49$ & $314.30 \pm 79.40$ & $323.50 \pm 61.45$ & $346.67 \pm 89.66$ & 27.40 & $<0.001^{*}$ \\
\hline $\mathrm{DC}$ & $35.64 \pm 4.26$ & $35.30 \pm 3.15$ & $37.27 \pm 4.48$ & $39.05 \pm 3.65$ & $40.23 \pm 3.46$ & 14.13 & $<0.001^{*}$ \\
\hline
\end{tabular}

Vt: Tidal volume; Vdalv: Alveolar dead space ventilation; $\mathrm{P}_{\mathrm{AET}} \mathrm{CO}_{2} ;$ Alveolar pressure gradient of end tidal $\mathrm{CO}_{2} ; \mathrm{PaCO}_{2} ;$ partial arterial pressure of carbon dioxide;

$\mathrm{PaO}_{2}$ : partial oxygen tension; $\mathrm{PaO}_{2} / \mathrm{FiO}_{2}$; $\mathrm{DC}$ : Dynamic compliance; $\mathrm{F}$ : Repeated analysis of variance [ANOVA]; ${ }^{*}$ : significant

Table [4]: Effect of PEEP on ultrasound among studied populations

\begin{tabular}{|c|c|c|c|c|c|c|c|c|c|c|c|c|c|}
\hline & \multicolumn{2}{|c|}{ P5 } & \multicolumn{2}{|c|}{ P6 } & \multicolumn{2}{|c|}{ P9 } & \multicolumn{2}{|c|}{$\mathrm{P} 12$} & \multicolumn{2}{|c|}{ P15 } & \multirow[t]{2}{*}{$\mathrm{F}$} & \multirow[t]{2}{*}{ P } \\
\hline & & Mean & SD & Mean & SD & Mean & SD & Mean & SD & Mean & SD & & \\
\hline \multirow{4}{*}{$\begin{array}{l}\text { Left } \\
\text { side }\end{array}$} & A4 & 5.60 & 1.63 & 5.43 & 1.45 & 5.13 & $1.38^{\# \$}$ & 4.47 & $1.31^{\# @ @ ~}$ & 3.10 & $0.88^{\# @ @ V}$ & 84.47 & $<0.001^{*}$ \\
\hline & A3 & 5.53 & 1.01 & 5.40 & 0.93 & 5.13 & $0.73^{\# \$}$ & 4.33 & $0.76^{\# \leqq}$ & 2.97 & $0.49 \# \$ @$ & 107.8 & $<0.001^{*}$ \\
\hline & $\mathrm{A} 2$ & 4.97 & 1.16 & 4.70 & 1.06 & 4.33 & $0.84^{\# \Phi}$ & 3.03 & $0.72^{\# @ @ ~}$ & 1.93 & $0.58^{\# @ @ ~}$ & 110.5 & $<0.001^{*}$ \\
\hline & A1 & 4.87 & 0.94 & 4.67 & 0.99 & 3.83 & $0.87 \# \$$ & 3.47 & $0.73^{\# @ @ ~}$ & 2.17 & $0.46^{\# @ @ V}$ & 98.75 & $<0.001^{*}$ \\
\hline \multirow{4}{*}{$\begin{array}{l}\text { Right } \\
\text { side }\end{array}$} & A4 & 5.23 & 1.28 & 5.27 & 1.39 & 4.73 & $1.11 \# \$$ & 3.93 & $1.08^{\# \$ @ ~}$ & 2.93 & $0.83^{\# @ @ ~}$ & 68.96 & $<0.001^{*}$ \\
\hline & A3 & 5.40 & 1.00 & 5.27 & 0.87 & 4.97 & $0.72 \# \$$ & 4.20 & $0.71 \# @ @$ & 2.90 & $0.55 \# \$ @$ & 93.56 & $<0.001^{*}$ \\
\hline & $\mathrm{A} 2$ & 4.93 & 1.14 & 4.53 & $1.01^{\#}$ & 4.10 & $0.88^{\# \$}$ & 2.83 & $0.65^{\# \nsubseteq @ ~}$ & 1.90 & $0.55^{\# @ @ ~}$ & 98.01 & $<0.001^{*}$ \\
\hline & A1 & 5.20 & 1.27 & 4.97 & 1.25 & 4.17 & $1.23^{\prime \$ \$}$ & 3.70 & $1.09 \# \$ @$ & 2.30 & $0.53^{\# @ \mathrm{~V}}$ & 87.65 & $<0.001^{*}$ \\
\hline
\end{tabular}

\# = Significant decreased when compared to PEEP 5; Significant decrease when compared to PEEP6; @= significant decrease when compared to PEEP9; $\sqrt{=}$ Significant decrease when compared to PEEP 12

\section{DISCUSSION}

Patients with ARDS are essentially at need of mechanical ventilation [MV] support. It could restore gas exchange and reduce work of breathing. Thus, improve the overall probability of survival. However, it is not devoid of risks and side effects [13]. There is a consensus on the superiority of lower tidal volumes ${ }^{[14]}$. However, there is little agreement on the selection of PEEP [15, 16]. In clinical practice, lower PEEP has been used [17], but low PEEP could lead to high oxygen desaturation[18] and lung injury worsened as evidenced by increased use of rescue therapies and mortality irrespective of the use of rescue therapies [19]. Extrinsic PEEP can be applied to improve oxygenation. According to Henry's law, the solubility of a gas in a liquid is positively 
correlated to the gas pressure above the solution surface. This was used for ventilation [either mechanical or noninvasive] in that increasing PEEP will be associated with an increase in the system pressure. This, in turn, increases the oxygen solubility and enhances oxygen ability to cross the alveolo-capillary membrane, and thus, the oxygen content of the blood will be increased. Extrinsic PEEP also could be used to enhance ventilationperfusion [VQ] mismatches. The application of positive airway pressure can open or support "splint" the collapsed alveoli, reducing atelectasis, improving the ventilation of alveoli, and, in turn, reducing VQ mismatch [20]. On the other side, high PEEP is associated with increased recruitment of alveoli, but at the same time could reduce cardiac output and further worsens injury of the lung [due to barotrauma or volutrauma][21]. Thus, optimization of PEEP to decrease hypoxemia or intrapulmonary shunting and to improve gas diffusion and oxygenation is of crucial importance. It could achieve by recruitment of collapsed alveoli [16, 22]. This is the idea adopted by the current study and achieved through gradual increments of PEEP, starting by PEEP 5 [the physiological PEEP], then increased to $6,9,12$, and 15; and the patient response had been checked and results correlated with ultrasound findings to investigate its use as a rapid, non-invasive tool to evaluate the condition.

The current work had been designed to investigate the role of the US in the management of ARDS by optimal PEEP. It included 30 patients who presented with ARDS. All underwent medical evaluation [full history taking, clinical examination, lab, and radiological investigations. The present study revealed that hypertension, diabetes, COPD, and hypothyroidism were reported in $63.3 \%, 66.7 \%$, $16.7 \%$, and $40.0 \%$, respectively. These results are comparable to those reported by Vieira et al..23] who said that the main comorbidity was systemic arterial hypertension [50.7\%], congestive heart failure [28.4\%], and COPD [8.9\%]. In line with the current study, an analysis of the LUNG-SAFE [Large study to UNderstand the Global impact of Severe Acute respiratory FailurE] study found that $13 \%$ of 2377 patients [13.3\% in the current study] treated for ARDS underwent tracheostomy[24]. The tracheostomy itself has become a more common practice. However, it had its own periprocedural risks such as bleeding, perforation of the posterior tracheal wall, injury of the thyroid gland, fistula [tracheoesophageal], and infections [25].

Regarding mortality, there is an upward trend in ARDS survival over the last four decades, which is attributed to developments in management strategies of ARDS, such as low tidal volume mechanical ventilation. Mortality rates decreased from $60-70 \%$ in 1980 s to $26-40 \%$ in mid-2000s [26, 27] [the current study had a mortality rate of $33.3 \%$ ]. One study analyzing data from 5159 patients with ARDS found that the crude mortality rate decreased from $35.4 \%$ in 1996 to $28.3 \%$ in 2013 . This was associated with significant trends of decline in daily fluid balance, tidal volume, and plateau pressure, and an increase in positive end-expiratory pressure over the 17 years[28]. Good monitoring tools could play a role in such improvements. The main findings of the current study are the progressive significant decrease of B-lines at different areas from the right and left lungs. All effects were significant at PEEP 9 , except at PEEP 6 . These results reflected that the changes on ultrasound were correlated with changes in different pulmonary variables. Lu ${ }^{[29]}$ reported that the clinical effect of alveolar recruitment could be assessed by measuring anatomical and/or functional lung recruitment. Anatomical alveolar recruitment defined by reaeration of previously poorly and nonaerated lung regions after increasing transpulmonary pressure, while functional lung recruitment marked by changes in respiratory physiological variables [increase in $\mathrm{PaO}_{2}$, decrease in $\mathrm{PaCO}_{2}$, and improvement of respiratory compliance] resulting from recruitment of lung units to participation in gas exchanges after PEEP application. These results had been confirmed in the current work.

The first introduction of lung ultrasound dates to the 1960s. It had the advantages of its easiness in use, totally non-invasive, and wide-spectrum of applications in critically ill patients. In addition, it confers regional lung representation of "real" images and artifacts $\left[{ }^{10,30]}\right.$. Also, and specifically in ARDS, it could differentiate between acute cardiogenic pulmonary edema from ARDS and is a good predictor of ARDS development[31].

When compared to Computed Tomography, lung ultrasound had a good accuracy in detection of pulmonary lesions ${ }^{[32]}$ and to assess changes in 
aeration in PEEP changes and development of ventilator-associated pneumonia [VAP] ${ }^{[33] .}$

In the current study, we started with PEEP 5, which in accordance with the previous study of Caironi et al.[34] who reported that patients with ARDS must be evaluated at PEEP 5 to check for alveolar recruitability. In addition, Bouhemad et al..[35] reported that PEEP 5 is the suggested level at which lung ultrasound is performed in patients with ARDS. Bouhemad et al.[33] reported that, with diffuse loss of aeration in patients with ARDS, higher levels of PEEP are required to induce lung recruitment when compared to ARDS patients with focal loss of aeration. This supported the protocol of gradual increments of PEEP used in the current study. This suggests that any maneuvers aimed at improving aeration improvement could be monitored by lung ultrasound[36].

A main controversial question is what is more protective and efficient for treating ARDS patients, high or low PEEP. Previous trials suggested that higher PEEP could be beneficial [16]. This suggestion had been confirmed in the current study, where the most effective response [guided by respiratory functions] had been obtained at PEEP levels of 12 and 15 . In addition, a meta-analysis carried by Briel et al. [19] showed a possible benefit of high PEEP setting in ARDS, which was associated with lower inhospital mortality and less need for MV by the day 28. Talmor et al. [37] study even confirmed that the PEEP 18 is associated with improved oxygenation and lung compliance than PEEP 12 and associated with improved adjusted 28-day mortality. However, Dasenbrook et al.[38], in another meta-analysis showed that there was no marked reduction of 28day mortality with high PEEP, without a significantly higher risk of barotrauma. The value of higher PEEP could be explained in the light of the driving pressure [the difference between a plateau and end-expiratory pressures], has been suggested as the mediator for this beneficial effects of the main three lungprotective ventilation [low tidal volume, low plateau pressure, and high PEEP] [39]. None of the three lung-protective measures were individually associated with low (decreased) mortality, but they acted to reduce driving pressure to exert their benefits. Mac Sweeney and McAuley[40] reported that a PEEP of $15 \mathrm{~cm} \mathrm{H} 2 \mathrm{O}$ could be appropriate in patients with ARDS to prevent lung injury and provide the optimal lung ventilation. Atelectatic areas of the lung can be re-expanded by the use of brief periods of sustained high transpulmonary pressure-usually followed by applying higher levels of PEEP to maintain and stabilize this newly reaerated region.

In addition to its use in monitoring and titration of PEEP and overall lung aeration, LUS also helps early diagnosis and appropriate treatment intervention for lung complications in ventilated patients. It had a very high diagnostic accuracy for pneumothorax and pleural effusions ${ }^{[41]}$. In line with the current work, Bouhemad et al.[35] reported that, in patients with ARDS, LUS evaluation of the overall lung or regional aeration may help of the disease severity, monitor therapeutic interventions, and patient's response. Tsubo et al.[42] studied the effect of applying several degrees of PEEP $[5,10$, and 15 $\mathrm{cm} \mathrm{H}_{2} \mathrm{O}$ ] as well as prone positioning, to examine aeration of the left lower lung in ARDS, and this represented the first use of US in the monitoring of the lung. They reported significant gas exchange improvement, the partial pressure of oxygen in arterial blood $\left[\mathrm{PaO}_{2}\right]$-to-a fraction of inspired oxygen $\left[\mathrm{FiO}_{2}\right]$ ratio, with increased PEEP or two hours after prone position. Gardelli et al. ${ }^{[43]}$ presented a case report of ARDS with real assessment and improvement of reaeration with transthoracic LUS after prone position. Bouhemad et al. [33] reported a significant correlation between LUS reaeration score at variable levels of PEEP and the recruited lung volume, as well as an oxygenation improvement. In a study conducted by Stefanidis et al. [44], of 15 early ARDS mechanically ventilated patients, lung collapse was measured by LUS before and after the use of incremental degrees of PEEP [5, 10, and 15 $\mathrm{CmH}_{2} \mathrm{O}$, with each level kept for 20 minutes]. All patients revealed a significant decrease of nonaerated areas as well as $\mathrm{PaO}_{2} / \mathrm{FiO}_{2}$ ratio improvement. Mojoli et al. [45] reported that LUS is a useful tool for the management of critically ill patients on mechanical ventilation. Zhao et al. [46] showed that, by grading different regions of the lungs, a global LUS could be computed. It quantifies the overall loss of aeration, with a strong correlation with lung weight and extra-vascular water in the lung. Thus, global LUS could provide a consistent and unbiased assessment tool for assessing acute respiratory failure and its severity. 
LUS could conveniently assess the morphology of the disease [focal vs. diffuse] at the bedside level. A re-aeration LUS can be computed to assess the PEEP-induced gain in end-expiratory lung volume; this does not strictly reflect to recruitment effect on the previously collapsed tissues ${ }^{[33]}$. Furthermore, Soummer et al. [47] reported that the LUS could monitor the weaning from MV. Finally, Bello and Blanco[ ${ }^{48]}$ conclude that LUS is an attractive, noninvasive tool to monitor lung recruitment in patients with ARDS. In addition, it is readily available, portable, and radiation-free tool. They added, clinically, the lung US score or lung reaeration score can be used to assess reaeration after PEEP. Lastly, Volpicelli et al. ${ }^{49]}$ reported that the main limitations to the use of LUS are the operator's level of expertise, dressings, thoracic burns, obesity, and subcutaneous emphysema. With wide availability, training, and technological improvement, such limitations are expected to be abolished with time. Smallwood et al. [50] confirmed this notion. They believe that the barriers to the use of LUS can easily be tackled. The costs of appliances continue to decrease as machines are becoming cheaper. The increased availability means training can often occur as part of the patient assessment and review on ward rounds.

On the other side, Chiumello et al.,[3] showed that LUS could assess regional and global lung aeration. However, it is not as reliable an imaging tool for evaluating PEEP-induced recruitment than the gold standard computed tomography. In addition, Xirouchaki et al.[30] reported own limitations of LUS. These include the inability of LUS to evaluate the lung with subcutaneous emphysema or large overlying dressings. Also, lung overinflation in high PEEP values is associated with potential barotrauma complications, which could not be detected by LUS. Another limitation is that LUS can only visualize parenchymal abnormalities adjacent to and extending to the pleura.

Despite these limitations, LUS is increasingly considered a vital imaging tool, playing a crucial role in clinical assessment and decision making. Again, it had its own significant advantages as it is a radiationfree bedside tool, had high sensitivity, specificity, and reproducibility. The current work appreciated its use as a monitoring tool for ARDS ventilated patients [44].
The strengths of the current work include the use of PEEP increments to tailor the patient response individually, with the use of readily available, portable ultrasound, which permits the daily monitoring and could guide the treatment protocol. However, the results could not be generalized due to the small sample size of the included populations. Thus, further studies are needed to validate this method in large ARDS populations.

In conclusion, gradual increments of PEEP helps to tailor the patient response on an individual basis. The use of readily available, portable ultrasound permits the daily monitoring and could guide the treatment protocol. Thus, it is advisable to be incorporated in the routine management protocol of patients with ARDS on mechanical ventilation.

Financial and Non-financial Relationships and Activities of Interest

None

\section{REFERENCES}

1. Chiumello D, Umbrello M, Sferrazza Papa GF, Angileri A, Gurgitano M, et al. Global and Regional Diagnostic Accuracy of Lung Ultrasound Compared to CT in Patients With Acute Respiratory Distress Syndrome. Crit Care Med. 2019 Nov; 47(11):1599-1606. [DOI: 10.1097/CCM. 0000000000003971].

2. Arbelot C, Ferrari F, Bouhemad B, Rouby JJ. Lung ultrasound in acute respiratory distress syndrome and acute lung injury. Curr Opin Crit Care. 2008 Feb;14(1):704. [DOI: 10.1097/MCC. 0b013e3282f43d05].

3. Chiumello D, Coppola S, Froio S, Mietto C, Brazzi L, Carlesso E, Gattinoni L. Time to reach a new steady state after changes of positive end expiratory pressure. Intensive Care Med. 2013 Aug; 39 (8):1377-85. [DOI: 10.1007/s00134-013-2969-x].

4. Chaari A, Bousselmi K, Assar W, Kumar V, Khalil E, Kauts V, Abdelhakim K. Usefulness of ultrasound in the management of acute respiratory distress syndrome. Int J Crit Illn Inj Sci. 2019 Jan-Mar; 9 [1]: 11-15. [DOI: 10.4103/IJCIIS.IJCIIS_30_18].

5. Tang KQ, Yang SL, Zhang B, Liu HX, Ye DY, Zhang HZ, $\mathrm{Ma} S$. Ultrasonic monitoring in the assessment of pulmonary recruitment and the best positive endexpiratory pressure. Medicine [Baltimore]. 2017 Sep; 96[39]:e8168. [DOI: 10.1097/MD.0000000000008168].

6. Neto AS, Simonis FD, Barbas CS, BiehI M, Determann RM, Elmer J, et al. Lung-Protective Ventilation with Low Tidal Volumes and the Occurrence of Pulmonary Complications in patients without Acute Respiratory Distress Syndrome: A Systematic Review and Individual 
Patient Data Analysis. Crit Care Med. 2015 Oct;43 [10]: 2155-63. [DOI: 10.1097/ CCM. 0000000000001189].

7. Bein T, Grasso S, Moerer O, Quintel M, Guerin C, Deja M, Brondani A, Mehta S. The standard of care of patients with ARDS: ventilatory settings and rescue therapies for refractory hypoxemia. Intensive Care Med. 2016 May;42[5]:699-711. [DOI: 10.1007/s00134-016-4325-4].

8. Sahetya SK, Goligher EC, Brower RG. Fifty Years of Research in ARDS. Setting Positive End-Expiratory Pressure in Acute Respiratory Distress Syndrome. Am J Respir Crit Care Med. 2017 Jun 1; 195 [11]:1429-1438. [DOI: 10.1164/rccm.201610-2035Cl].

9. Chiumello D, Marino A, Brioni M, Cigada I, Menga F, Colombo A, et al. Lung Recruitment Assessed by Respiratory Mechanics and Computed Tomography in Patients with Acute Respiratory Distress Syndrome. What Is the Relationship? Am J Respir Crit Care Med. 2016; 193 [11]: 1254-63. [DOI: 10.1164/rccm.20150714130C].

10. Pesenti A, Musch G, Lichtenstein D, Mojoli F, Amato MBP, Cinnella G, Gattinoni L, Quintel M. Imaging in acute respiratory distress syndrome. Intensive Care Med. 2016 May; 42 [5]:686-698. [DOI: 10.1007/s00134-0164328-1].

11. Vignon $P$, Repessé $X$, Vieillard-Baron A, Maury E. Critical care ultrasonography in acute respiratory failure. Crit Care. 2016; 20[1]:228. [DOI: 10.1186/s13054-0161400-8]

12. Dietrich CF, Mathis G, Cui XW, Ignee A, Hocke M, Hirche TO. Ultrasound of the pleurae and lungs. Ultrasound Med Biol. 2015; 41(2):351-65. [DOI: 10.1016/j.ultrasmedbio. 2014.10.002].

13. Kim KT, Morton S, Howe S, Chiew YS, Knopp JL, Docherty $\mathbf{P}$, et al. Model-based PEEP titration versus standard practice in mechanical ventilation: a randomised controlled trial. Trials. 2020 Feb 1; 21 [1]:130. [DOI: 10.1186/s13063-019-4035-7].

14. Girard TD, Bernard GR. Mechanical ventilation in ARDS: a state-of-the-art review. Chest. 2007; 131:921-9. [DOI: 10.1378/chest.06-1515].

15. Brower RG, Lanken PN, Macintyre N, Matthay MA, Morris A, Ancukiewicz M, et al. Higher versus lower positive end-expiratory pressures in patients with the acute respiratory distress syndrome. $\mathrm{N} \mathrm{Engl} \mathrm{J} \mathrm{Med.} \mathrm{2015;}$ 373: 327-36. [DOI: 10.1056/NEJMoa1511939].

16. Mercat A, Richard JC, Vielle B, Jaber S, Osman D, Diehl $\mathrm{JL}$, et al.; Expiratory Pressure (Express) Study Group. Positive end-expiratory pressure setting in adults with acute lung injury and acute respiratory distress syndrome: a randomized controlled trial. JAMA. $2008 \mathrm{Feb}$ 13; 299(6):646-55. [DOI: 10.1001/jama.299.6.646].

17. Gattinoni L, Carlesso E, Brazzi L, Caironi P. Positive endexpiratory pressure. Curr Opin Crit Care. 2010; 16:39-44. [DOI: 10.1097/MCC.0b013 e3283354723].
18. Guerin $\mathrm{C}$. The preventive role of higher PEEP in treating severely hypoxemic ARDS. Minerva Anestesiol. 2011 Aug;77(8):835-45. PMID: 21730932.

19. Briel M, Meade M, Mercat A, Brower RG, Talmor D, Walter SD, et al. Higher vs lower positive end-expiratory pressure in patients with acute lung injury and acute respiratory distress syndrome. J Am Med Assoc. 2010; 303:865-73. [DOI: 10.1001/jama.2010.218].

20. Mora Carpio AL, Mora JI. Positive End-Expiratory Pressure [PEEP]. 2020 Apr 27. In: StatPearls [Internet]. Treasure Island [FL]: StatPearls Publishing; 2020 Jan-. PMID: 28722933.

21. Thammanomai A, Hamakawa H, Bartolák-Suki E, Suki B. Combined effects of ventilation mode and positive end-expiratory pressure on mechanics, gas exchange and the epithelium in mice with acute lung injury. PLoS One. 2013; 8:1-10. [DOI: 10.1371/journal.pone. 0053934]

22. de Matos GFJ, Stanzani F, Passos RH, Fontana MF, Albaladejo R, Caserta RE, et al. How large is the lung recruitability in early acute respiratory distress syndrome: a prospective case series of patients monitored by computed tomography. Crit Care. 2012; 16:R4. [DOI: 10. 1186/cc10602]

23. Vieira JR, Castro MR, Guimarães TP, Pinheiro AJT, Figueiredo ACTC, Martins BJ, Carmo DRD, Oliveira WA. Evaluation of pulmonary B lines by different intensive care physicians using bedside ultrasonography: a reliability study. Rev Bras Ter Intensiva. 2019 Oct 14; 31[3]:354-360. [DOI: 10.5935/0103-507X.20190058].

24. Abe T, Madotto F, Pham T, Nagata I, Uchida M, Tamiya N, Kurahashi K, Bellani G, Laffey JG; LUNG-SAFE Investigators and the ESICM Trials Group. Epidemiology and patterns of tracheostomy practice in patients with acute respiratory distress syndrome in ICUs across 50 countries. Crit Care. 2018 Aug 17; 22(1):195. [DOI: 10.1186/s13054-018-2126-6]

25. Cipriano A, Mao ML, Hon HH, Vazquez D, Stawicki SP, Sharpe RP, Evans DC. An overview of complications associated with open and percutaneous tracheostomy procedures. Int J Crit IIIn Inj Sci. 2015 Jul-Sep;5(3):17988. [DOI: 10.4103/2229-5151.164994].

26. Esteban A, Frutos-Vivar F, Muriel A, Ferguson ND, Peñuelas $\mathrm{O}$, Abraira $\mathrm{V}$, et al. Evolution of mortality over time in patients receiving mechanical ventilation. $\mathrm{Am} \mathrm{J}$ Respir Crit Care Med. 2013 Jul 15; 188 (2):220-30. [DOI: 10.1164/rccm.201212-2169OC].

27. Ochiai R. Mechanical ventilation of acute respiratory distress syndrome. J Intensive Care. 2015 May 29; 3(1):25. [DOI: 10.1186/s40560-015-0091-6].

28. Zhang Z, Spieth PM, Chiumello D, Goyal H, Torres A, Laffey JG, Hong Y. Declining Mortality in Patients With Acute Respiratory Distress Syndrome: An Analysis of the Acute Respiratory Distress Syndrome Network Trials. Crit 
Care Med. 2019 Mar; 47(3):315-323. [DOl: 10.1097/ CCM.0000000000003499].

29. Lu Q. How to assess positive end-expiratory pressureinduced alveolar recruitment? Minerva Anestesiol. 2013 Jan;79[1]:83-91. PMID: 23135694.

30. Xirouchaki N, Kondili E, Prinianakis G, Malliotakis $P$, Georgopoulos D. Impact of lung ultrasound on clinical decision making in critically ill patients. Intensive Care Med. 2014 Jan;40(1):57-65. [DOI: 10.1007/s00134-0133133-3]

31. Leblanc D, Bouvet C, Degiovanni F, Nedelcu C, Bouhours G, Rineau E, et al. Early lung ultrasonography predicts the occurrence of acute respiratory distress syndrome in blunt trauma patients. Intensive Care Med. 2014; 40(10):1468-74. [DOI: 10.1007/s00134014-3382-9].

32. Huang D, Ma H, Xiao Z, Blaivas M, Chen Y, Wen J, et al. Diagnostic value of cardiopulmonary ultrasound in elderly patients with acute respiratory distress syndrome. BMC Pulm Med. 2018; 18(1):136. [DOI: 10.1186/s12890-0180666-9].

33. Bouhemad B, Brisson H, Le-Guen M, Arbelot C, Lu Q, Rouby JJ. Bedside ultrasound assessment of positive end-expiratory pressure-induced lung recruitment. Am J Respir Crit Care Med. 2011 Feb 1; 183(3):341-7. [DOl: 10.1164/rccm.201003-03690C].

34. Caironi $P$, Carlesso E, Cressoni M, Chiumello D, Moerer 0 , Chiurazzi $\mathrm{C}$, et al. Lung recruitability is better estimated according to the Berlin definition of acute respiratory distress syndrome at standard $5 \mathrm{~cm} \mathrm{H} 2 \mathrm{O}$ rather than higher positive end-expiratory pressure: a retrospective cohort study. Crit Care Med. 2015 Apr; 43 (4): 781-90. [DOI: 10.1097/CCM.0000000000000770].

35. Bouhemad B, Mongodi S, Via G, Rouquette I. Ultrasound for "lung monitoring" of ventilated patients. Anesthesiology. 2015; 122(2):437-47. [DOI: 10.1097/ ALN.0000000000000558].

36. Via G, Storti E, Gulati G, Neri L, Mojoli F, Braschi A. Lung ultrasound in the ICU: from diagnostic instrument to respiratory monitoring tool. Minerva Anestesiol. 2012 Nov;78(11):1282-96. PMID: 22858877.

37. Talmor D, Sarge T, Malhotra A, O'Donnell CR, Ritz R, Lisbon A, Novack V, Loring SH. Mechanical ventilation guided by esophageal pressure in acute lung injury. $\mathrm{N}$ Engl J Med. 2008 Nov 13; 359 (20): 2095-104. [DOl: 10.1056/NEJMoa0708638].

38. Dasenbrook EC, Needham DM, Brower RG, Fan E. Higher PEEP in patients with acute lung injury: a systematic review and meta-analysis. Respir Care. 2011 May;56(5):568-75. [DOI: 10.4187/ respcare.01011].

39. Amato MB, Meade MO, Slutsky AS, Brochard L, Costa EL, Schoenfeld DA, et al. Driving pressure and survival in the acute respiratory distress syndrome. N Engl J Med. 2015; 372(8):747-55. [DOI: 10.1056/NEJMsa1410639].
40. Mac Sweeney R, McAuley DF. Acute respiratory distress syndrome. Lancet 2016; 388: 2416-30. [DOI: 10.1016/ S0140-6736 [16]00578-X].

41. Rodriguez Lima DR, Yepes AF, Birchenall Jiménez $\mathrm{Cl}$, Mercado Díaz MA, Pinilla Rojas DI. Real-time ultrasound-guided thoracentesis in the intensive care unit: prevalence of mechanical complications. Ultrasound J. 2020 6;12[1]:25. [DOI: 10.1186/s13089-020-00172-9].

42. Tsubo T, Sakai I, Suzuki A, Okawa H, Ishihara H, Matsuki A. Density detection in dependent left lung region using transesophageal echocardiography. Anesthesiology. 2001 May;94(5):793-8. [DOl: 10.1097/00000542-200105000-00017].

43. Gardelli G, Feletti F, Gamberini E, Bonarelli S, Nanni A, Mughetti M. Using sonography to assess lung recruitment in patients with acute respiratory distress syndrome. Emerg Radiol. 2009 May; 16 (3): 219-21. [DOI: 10.1007/s10140-008-0734-1].

44. Stefanidis K, Dimopoulos S, Tripodaki ES, Vitzilaios K, Politis P, Piperopoulos P, Nanas S. Lung sonography and recruitment in patients with early acute respiratory distress syndrome: a pilot study. Crit Care. 2011 Aug 4; 15(4):R185. [DOI: 10.1186/cc10338].

45. Mojoli F, Bouhemad B, Mongodi S, Lichtenstein D. Lung Ultrasound for Critically III Patients. Am J Respir Crit Care Med. 2019 Mar 15; 199(6):701-714. [DOI: 10.1164/rccm. 201802-0236Cl].

46. Zhao Z, Jiang L, Xi X, Jiang Q, Zhu B, Wang M, Xing J, Zhang $\mathbf{D}$. Prognostic value of extravascular lung water assessed with lung ultrasound score by chest sonography in patients with acute respiratory distress syndrome. BMC Pulm Med. 2015 Aug 23; 15:98. [DOI: 10.1186/s12890-015-0091-2].

47. Soummer A, Perbet S, Brisson H, Arbelot C, Constantin JM, Lu Q, Rouby JJ; Lung Ultrasound Study Group. Ultrasound assessment of lung aeration loss during a successful weaning trial predicts postextubation distress. Crit Care Med. 2012 Jul;40(7):2064-72. [DOI: 10.1097/ CCM.0b013e31824e68ae].

48. Bello G, Blanco P. Lung ultrasonography for assessing lung aeration in acute respiratory distress syndrome: A narrative review. J Ultrasound Med. 2019; 38[1]:27-37. [DOI: 10.1002/jum.14671].

49. Volpicelli G, Elbarbary M, Blaivas M, Lichtenstein DA, Mathis G, Kirkpatrick AW, et al.. International evidencebased recommendations for point-of-care lung ultrasound. Intensive Care Med. 2012 Apr;38(4):577-91. [DOI: 10.1007/s00134-012-2513-4]

50. Smallwood N, Miller A, Walden A, Hew M, Tay TR, Rahman NM. Should point-of-care ultrasonography replace stethoscopes in acute respiratory failure? BMJ. 2019 Aug 30; 366:I5225. [DOI: 10.1136/bmj.|I225]. 


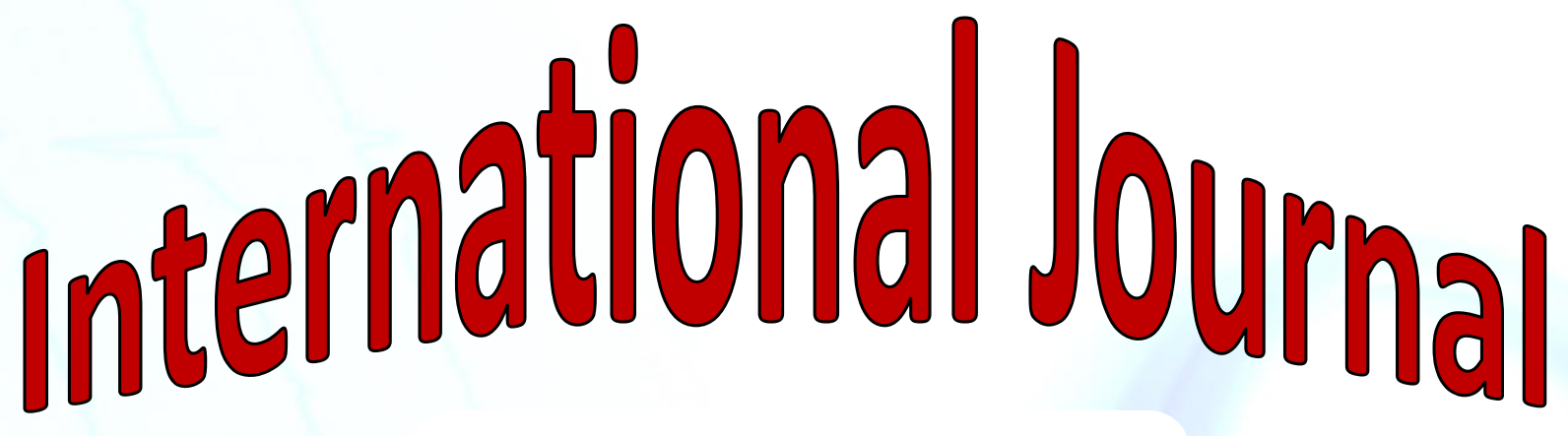

https://ijma.journals.ekb.eg/

Print ISSN: 2636-4174

Online ISSN: 2682-3780

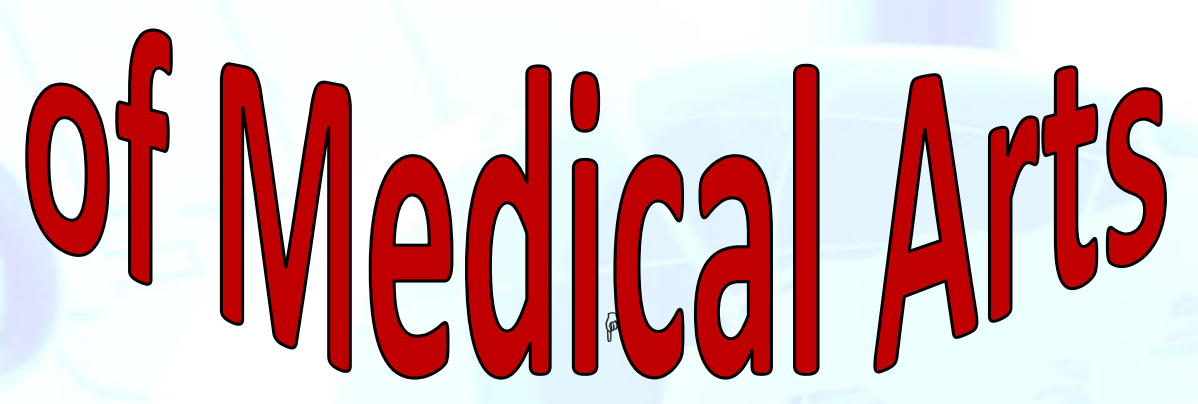

